\title{
More grist for Dingell's mill
}

\section{Washington}

US Congressman John Dingell, who heads the powerful congressional subcommittee on oversight and investigations that pursued the Baltimore affair, is once again exercised over a case of alleged scientific misconduct. Last month, he wrote to James Wyngaarden, outgoing director of the National Institutes of Health (NIH), to ask why it was that in a recent case of alleged plagiarism, an NIH panel had "made only a finding of "serious misconduct' but not a finding of fraud". And he asked Wyngaarden to describe "your process for criminal referrals".

Wyngaarden's reply makes it plain that $\mathrm{NIH}$ is not being soft-hearted. He explains that the concept of 'misconduct' includes fraud, something that is stressed in both the draft and final Department of Health and Human Services (HHS) rule concerning misconduct (see accompanying article). And he makes clear that the possibility of criminal action is being considered by the HHS Office of the Inspector General in the standard way.

But Wyngaarden makes no comment on another major part of Dingell's letter. There Dingell is critical of the role of Daniel Koshland, editor of the US journal Science, in the case of plagiarism.

The case (see Nature 340, 173; 20 July $1989)$ involves an allegation that a paper published in Science $(236,1678 ; 1987)$ by C. David Bridges, at that time a researcher at Baylor College of Medicine in Houston, plagiarized information from a manuscript by Paul S. Berstein, Wing C. Law and Robert R. Rando of Harvard Medical School. The Rando paper had been sent to Bridges for review and was later published in Proceedings of the National Academy of Sciences (PNAS 84, 1849; 1987).

Dingell writes "It is disburbing to me that in this instance a distinguished editor of a leading American journal was aware of possible scientific misconduct and not only took no steps to prevent an injustice from occurring, but actually allowed publication of the stolen material."

Dingell bases his assertion on statements in a letter that Rando wrote to Koshland shortly before the paper was published explaining there were some difficulties with it. But it is not clear that the difficulties were portrayed as serious. In his letter to Koshland, Rando explains that he had met Bridges and entered into an agreement with him that the Science paper should be modified to recognize Rando's work.

The relevant section of the letter from Rando says:

"I enclose an article which my co-workers and I recently published in $P N A S$, on very similar material.

I saw Prof. Bridges at the ARVO meeting in
Sarasota, FLA. on May 7. We reached a verbal agreement that certain changes should be made in the Science article to indicate that our paper had been sent to Prof. Bridges for review in July, 1986. The changes we agreed on are enclosed. I believe that it is very important that there be no discrepancies between the enclosed changes and those sent to Science by Prof. Bridges."

But there were discrepancies between Rando's changes and the published changes, Science taking the view that, as Koshland puts it, "the author is the final arbiter of changes in his own paper". The question that interests the Dingell subcommittee is whether Koshland should have read the letter from Rando as indicating plagiarism. Rando has told Nature that the letter "raised a little bit of a flag from me but I did not say I suspected plagiarism". But Dingell claims that Rando believes that "the letter to $\mathrm{Dr}$ Koshland should have raised serious concerns". Koshland's view, as reported in the latest issue of Science, is that Rando's letter "only raised issues about appropriate reference to his work".

The question now is whether the affair will rest as it is, or whether an attempt will be made to resolve contrary opinions by further congressional action. Sources close to the subcommittee speak of a possible hearing on the topic of misconduct in the peer review process.

Koshland has not himself made any direct editorial statement about the affair in the pages of Science, instead having "turned his own reporters loose" to investigate and even to interview him. He says this is necessary because "we are very careful to keep privileged information in the editorial department, we don't leak to the news department". Science's investigative team have used the Freedom of Information Act to obtain documents (as has Nature) and not found any skeletons in Science's cupboards.

Bridges, an Englishman who formerly carried out research at the MRC Vision Research Unit in the Institute of Ophthalmology in London, maintains his complete innocence of any of the charges made in the NIH report. He states firmly that he has been "framed". That Bridges might be the victim of a conspiracy was discussed by the investigatory committee and Bridges points out that the preliminary NIH report stated that "vindictiveness" may have motivated actions against him. According to Wyngaarden, Bridges will have an opportunity to appeal.
Alun Anderson

\section{New rules are finalized}

\section{Washington}

STRICTER regulations to ensure that institutions have procedures in place to investigate possible misconduct in science distinguish the 'final rule' on misconduct that is about to be published by the US Department of Health and Human Services. The rule also provides a new requirement that all institutions submit "aggregate information on allegations, inquiries and investigations" each year. That information should help provide, for the first time, central records of the frequency of misconduct and allegations of misconduct.

The new rule applies to institutions receiving financial assistance from the Public Health Service and includes the National Institutes of Health (NIH).

A 'Notice of Proposed Rule Making' which set out initial proposals for public review was published last September. The final rule takes into account the 139 comments received and the two new scientific integrity offices set up this year to take care of scientific misconduct in the Public Health Service (see Nature 340, 3; 6 July 1989). The definition of misconduct is changed to make it clear that "honest error or honest differences in interpretations or judgements of data" are excluded and that misconduct means the fabrication, falsification and plagiarism of data.
The final rule retains the draft proposal that an institution must be able to inquire "immediately" into an "allegation or other evidence of possible misconduct" and complete its inquiry within 60 days. If a full investigation is found necessary, it must begin within 30 days and be completed within a further 120 days.

Extra guidance is given on the way an investigation is to be performed. The final rule requires "examination of all documentation, including ... research data and proposals, publications, correspondence and memoranda of telephone calls". All involved are to be interviewed and summaries of what they said given to them for "comment or revision". And the rule helps whistleblowers by adding a requirement for "diligent efforts" to be made "to protect the positions and reputations of those persons who, in good faith, make allegations". The draft version provided only for the reputations of those "alleged to have engaged in misconduct when allegations are not confirmed".

The final rule deliberately does not deal with measures "to foster scientific integrity" and lists, as issues that remain to be addressed, the retention of laboratory data, authorship practices ['ghost' and multiple authorship], and the performance of audits or studies to prevent scientific misconduct. 